\title{
An analysis of a Borderline Personality Disorder case with compulsive sexual perversions according to Interpersonal Motivational Systems and Metacognitive functioning models* by Tonino Cantelmi** and Emiliano Lambiase**
}

\section{Introduction}

To this date, there is still no satisfactory theory within the cognitive framework explaining the onset and the psychological dynamics of sexual perversions, which are often considered permanent and hardly understandable. The aim of our study is to open a breakthrough in this perspective and propose some conceptual and clinical hypotheses on this type of non-respondent patients. We decided to refer to two cognitive models, which we have already used for the conceptualisation and therapeutic work with serious disorders: the Interpersonal-Metacognitive model (for the metacognitive functioning) and the Cognitive-Evolutionary model (for the Interpersonal Motivational Systems, or IMS). We will first describe these theoretical models, then we will analyse the way they can be applied to the study of sexuality, starting with some theoretical reflections - developed from the clinical practice and we will eventually present a case study in which these conceptualizations will be used to explain the disorder and our therapeutic choices.

* This paper is an updated version, and translated into English by Dr. Daniela Cerboni, of the following article in Italian: Lambiase E. and Cantelmi T. (2011), "Un caso di dipendenza sessuale: vantaggi di un'analisi condotta in termini di sistemi motivazionali e di sottofunzioni metacognitive". Psicoterapia Cognitiva e Comportamentale, 17, 1: 99-118.

${ }^{* *}$ Institute of Cognitive Interpersonal Therapy, Rome, Italy. 


\section{Theoretical background}

\subsection{Metacognition according to the Cognitive-Interpersonal model}

For what concerns the construct of metacognition and of metacognitive sub-functions, Third Centre researchers developed an initial model of metacognitive function (Semerari, 1999b; Dimaggio and Semerari, 2003) based on the analysis of transcripts of the therapeutic work done with patients affected by personality disorders. This model has been subsequently reviewed and modified (e.g. Carcione et al., 2008; Dimaggio et al., 2008; Dimaggio et al., 2009). According to these authors, the metacognitive function can be split into three areas: Self-Reflection, Understanding others' mind/Decentration and Mastery, and each of these comprehends several sub-functions.

Self-Reflection includes Monitoring, Differentiation and Integration. Monitoring is characterised by the ability of distinguishing, recognising and defining one's mental representations and emotions (Identification) and by the ability of establishing links among the elements of a mental state and between that mental state and the connected behaviour (Relationship among Variables). Differentiation refers to the ability of distinguishing among various classes of representations (e.g. dreams, fantasies, beliefs, hypotheses, etc.) and between representations and reality. Integration is defined as the ability of reflecting on one's mental states and contents so to establish a hierarchical order of relevance which allows individuals to coherently adapt to reality and pursue their goals. It is the function we use when we are describing our own mental scenarios or when we do our own internal debating in a narrative form, in order to provide a continuity meaning to our personal and interpersonal aspects.

The sub-functions of Understanding others' mind are Monitoring and Decentration. The former includes the ability of catching others' emotions and make plausible inferences about their thoughts (Identification) and also the ability of catching those factors that may influence their mental state (Relationship among Variables). Decentration assesses the ability of describing others' mental states by formulating hypotheses that are independent from one's own perspective, mental functioning and personal involvement in the relationship.

Mastery refers to the set of one's own abilities to operate on representations and mental states, by creating and experimenting strategies aimed at solving cognitive tasks or managing negative emotions which can be a source of individual suffering. Mastery strategies can be split into separate categories according to the increasing complexity of the metacogni- 
tive operations entailed. First level strategies imply a low reflection effort, expressed e.g. as modification of the mental state, direct action on the organism, aware avoidance of feared situations, or search for interpersonal support. Second level strategies require a higher reflection effort and include voluntary self-imposition or self-inhibition of a conduct, active modification of attention and concentration, or voluntary thinking/ not thinking of a problem. Third level strategies require a high reflection effort and include rational critique and some belief at the basis of a problematic state, the use of others' mental states in order to regulate interpersonal problems and, eventually, a mature acceptance of personal limitations in managing oneself and influencing the events.

Third Centre authors have also developed an assessment interview of metacognition - Assessment of Interpersonal Motivation in Transcripts, AIMIT - (Semerari et al., 2008) to be used in the course of the assessment interview with the patient, and a Metacognition Assessment Scale (MAS, Carcione et al., 2010) for the analysis of psychotherapy transcripts. We will refer to the latter tool for the analysis of transcripts that we will present further on in this document.

\subsection{Interpersonal Motivational Systems according to Evolutionary- Cognitivism}

According to the Interpersonal Motivational Systems (IMS) in the evolutionary perspective, some predispositions which are meant to process and actualize some forms of social interaction beneficial to survival are innate in humans too. Each of these predispositions regulates specific areas of the interpersonal behaviour (Lichtenberg, 1989; Lichtenberg, Lachmann and Fosshage, 1992, 1996; Liotti, 2001, 2005; Liotti and Monticelli, 2008). Although innate, they appear to be strongly influenced by individual experience and learning (Liotti and Monticelli, 2008). These predispositions can be defined in relationship to the goal they are meant to pursue and, as such, they can be considered interpersonal "motivational" systems (IMS). According to Liotti and coll., they are namely: attachment, competition, caregiving, sexuality, cooperation and, probably, social game and group affiliation (Liotti, 2005; Liotti and Monticelli, 2008).

The activation of these innate systems regulates the processing and management of emotions before the emergence of a conscious ability to recognise and modulate them (Liotti, 2005). The construction of the interpretation of emotions and their management are therefore interpersonal processes and in order for this process to be healthy and functional to development and adapta- 
tion, it is necessary that the infant's emotions are adequately mirrored by the caregiver (eg. Main, 1991; Fonagy and Target, 2001).

These mirrorings are indeed at the basis of the development of metacognitive abilities which allow us, among other functions, to interpret and manage our emotions. In this process, attachment relationships would play a fundamental role, since the experience of primary interactions of request/offer of care constitutes the first and primary step which orientates the subsequent development of the capacity of regulating all types of emotions. Practically, the attachment system and the Internal Working Models (IWM), which control its activity, would play a very particular and central role in the regulation of both the typical attachment emotions and those of all other motivational systems.

Emotional exchanges which characterise a secure attachment relationship entail that the adult is able to react promptly and adequately to the infant's signals with responses that favour the amplification of the positive emotional states and the control of the negative ones. Repeated experiences of this kind are recorded in the implicit memory, they generate expectations and therefore give origin to mental patterns or attachment models (Internal Working Models). An internal working model of attachment is a form of mental pattern or model through which the implicit memory creates generalisations of past experiences. Such models allow a quicker interpretation of new experiences and help predict, in the various situations, the immediate consequences most likely to happen. The IWMs of attachment play, therefore, a crucial role in giving origin to the mental system of self-regulation of emotions by influencing the way the individual is able to soothe himself or seek comfort, and they are at the basis of a negative attitude in connection with one's emotions of request for help.

When attachment needs are satisfied, it is possible for the child to turn the attention to other needs and motivational systems. When this does not occur, instead, there is either no space for the development of other motivational systems or they can be activated in a dysfunctional way in order to satisfy the attachment needs.

For a more in-depth study of motivational systems the reader can refer to the work of Liotti (2001, 2005; Liotti and Monticelli, 2008).

\subsection{Sexuality and Metacognition}

The relationship between the sexual motivational system and attachment has been recently object of many studies (for specific reviews see Eagle, 
2005; Cantelmi and Lambiase, 2007; Diamond, Blatt and Lichtenberg, 2007; Del Giudice, 2009 and relevant comments). However, almost none of these works explicitly conceptualizes this relationship in connection with metacognitive functioning and, in the few cases they did, the concept was only briefly addressed.

Yet, $t$ is in the course of attachment dynamics that the infant learns how to recognise, appreciate and manage the emotions that it will subsequently experience in connection with the activation of other innate motivations linked to the various IMS; and it is, again, in the course of attachment dynamics that it starts developing metacognitive abilities. Besides, as stated by Liotti, Cortina and Dazzi (2008) and Manaresi et al. (2008), it is important to also consider how the activation of the other motivational systems can influence the regulation of emotional experience. As a matter of fact, «also positive or negative experiences regulated by different attachment IMS might positively or negatively influence the mentalizing capacity» (Manaresi et al., 2008, p. 66). The relationship between attachment, metacognition and sexuality is, therefore, a tight and multidirectional one.

Among the motivational systems, attachment is the first one to be activated from an ontological perspective. Subsequently, toward the second year of age, the sexual motivational system emerges (Lieberman, 1996; Mahler, Pine and Bergman, 1975; Roiphe and Galenson, 1981; Ammaniti, Nicolais and Speranza, 2007), which, however, seems to arise intensely between 12 and 25 years of age (Crittenden, 2002). In particular, this life cycle requires the development of integration strategies which allow the individual to find solutions to various motivations, including those resulting from other IMS. In order for this to occur, it is important that the subject is capable of, or able to develop, a good level of metacognitive functioning. Differently, it would be particularly difficult for them to recognise the drives coming from the various IMS, regulate their intensity or be able to integrate these drives within a unified narrative plot.

The existing strategies of self-protection and protection-seeking must be reorganised, sexual strategies must be developed and these need to be integrated in such a way that a variety of attachment relationships can be established, which are co-existing and mutually supportive. In middle and late adolescence a friend can even become an object of sexual desire. This creates a new way to experience intimacy and express affection, and it also offers new incentives to maintain one's relationships at stressful times. Besides, sexual desire ensures new ways to seek comfort and reduce emotional activation (Crittenden, 2002).

It is evident how, in order to fulfil these tasks, adolescents must have or develop sufficient metacognitive abilities, allowing them to reorganise their 
mental states and their interpersonal patterns within, and in function of, a wider and more complex reality.

On the contrary, if for example the subject is not able to integrate the various motivational drives which are entailed in an adult intimate relationship, he/she can get to the point of having to fragment them, seeking satisfaction either in multiple relationships or according to dysfunctional modalities. Again, the subject may not be able to recognise the drives of different IMS or to adequately relate to others, due to his/her incapability of understanding others' impulses. They may start using sexual behaviour to satisfy their attachment needs in a dysfunctional way, in relating to themselves (e.g. compulsive masturbation or use of pornography) or to others (cf. Cantelmi and Lambiase, 2007).

On the other hand, most part of the brain development in adolescence occurs in brain areas that are crucial to the regulation of emotions and behaviours. In particular, changes in arousal and motivation consequent to pubertal maturation are prior to the development of regulatory abilities, creating a fracture between the affective experience and the capacity of regulating excitement and motivation (Steinberg, 2005).

The metacognitive development reached up to this point is not sufficient to allow full management of the intense emotions that adolescents typically experience. Therefore, further development and maturation stages will be needed, which are favoured or hindered by - among other factors - the sexual IMS activation and by the strategies that the subject will develop in order to manage his/her sexuality in the relationship with oneself and with others. If for some adolescents unaffected by disorders the sexual drive provides a strong motivation to improve themselves and to reorganize their expression of earlier motivational systems, others, who instead confuse sexual satisfaction with seeking comfort, may start engaging in frequent or insecure sexual behaviours in order to regulate their emotional state.

Others more may find out that being precociously sexually aware or promiscuous allows them to break their isolation, or they may consent to sexual requests in order to feel accepted. Besides, if the sexual and seeking-comfort behaviours (sexuality and attachment) can be confused, the same can happen with sex and aggression (sexuality and competition), particularly in men.

Aggression, hence, can be sexually expressed and both partners may confuse it with love. These distortions could be due to a failure to recognise one's own mental contents, which would make the subject incapable of distinguishing the drives coming from different IMS, or to a disorder in the capacity of integrating distinct motivations in a coherent narrative.

Besides, in order for someone to become an attachment figure it is necessary that they are perceived as familiar and have a predictable behaviour. 
It does not occur, in theory, that one gets attached to someone they perceive as unpredictable or unknown. According to some authors, it is only in this type of bond that sexual desire can develop in a healthy and functional way.

On the contrary, Eagle (2005) highlights how sexual excitement is reduced by familiarity and predictability and how, rather, it is intensified by novelty, unfamiliarity and diversity. One is confronted, therefore, with the necessity of integrating motivations which bond us to our partner with those driving us to get to know new ones. Such an integration can be particularly challenging if, for example, the integration functions or the emotional regulatory abilities are not adequately developed, and this may bring the subject to start satisfying the drives coming from different IMS in a dysfunctional way, e.g. having parallel relationships.

There are also relevant differences between adult attachment and infancy attachment. Firstly, infancy attachments are typically complementary, i.e. the attachment figure provides care but does not receive any in return, while the child seeks security but does not provide it (Cassidy and Shaver, 1999).

On the contrary, adult attachment is typically reciprocal. A second difference consists in the fact that in adulthood the attachment figure is a peer and, often, a sexual partner too. The most typical form of adult attachment entails, therefore, an integration among different IMS: attachment, caregiving, and sexual motivational systems (Shaver and Hazan, 1992). Further, it is necessary to observe that, rather often, one of the reasons for seeking contact in adulthood - at least in the initial stages of a relationship - is sexual attraction (Weiss, 1982; Shaver, Hazan and Bradshaw, 1998; Tombolini and Liotti, 2000). Nevertheless, if attraction and sexual passion are fundamental requirements for satisfaction at the beginning of a relationship, a few years later it is the capacity of both partners to offer reciprocal comfort and care to become of primary importance (Shaver and Hazan, 1992).

In the adult attachment dynamics that we described above, the functions of self-reflection, understanding of others' mind and integration appear of fundamental relevance.

It is very important to be aware of our own and the partner's needs and states of mind to be able to establish a truly reciprocal relationship and to go beyond the stage of initial attraction by integrating the needs specific to the various IMSs. It is also thanks to these metacognitive abilities that the partners can reciprocally satisfy their needs for comfort and care, which allow the couple to evolve beyond the phase of initial attraction and make it possible to both confirm and change their respective Internal Working Models (IWM). Only the sufficiently accurate, i.e. up-to-date models, will produce an adaptive behaviour in relationships. 
Differently, an insecure form of attachment between partners constitutes the basis for unsatisfactory or incomplete sexual experiences. In this type of relationships, sex can be used in replacement of other relational and non sexual needs, and any sexual pleasure can be inhibited by painful emotions linked to the attachment system (e.g. fear, anger, pain), which the subject is not able to manage. Secure attachment is instead a necessary condition for the couple to experience sex in a free, fulfilling and non conflicting way, and in order for this to happen the presence of sufficiently developed metacognitive abilities is fundamental.

What discussed so far is fundamentally relevant to the insecure forms of attachment in association with metacognitive malfunctioning. According to the level of anxiety or avoidance, sexual behaviour will be directed to satisfy some needs instead of others (cf. Cantelmi and Lambiase, 2007), and can be connected with some different cognitive and emotional profiles (Crittenden and Landini, 2011). However, when attachment is disorganized, according to Shane M., Shane E. and Gales (1999) the typical sexual experience is actually not genuinely sexual. In this case, the needs of one's Self and those of the Self-with-the-Other are not satisfied and there is no love, no intimacy or sexual pleasure of any kind. In addition, there is no integrated Self, no consolidated Self, or any strong bond with the other person. The experience of these people is not a sexually pleasurable one and, sometimes, does not even involve their genitals. It is rather, and usually, unpleasant and painful, or anaesthetic - the latter in connection with the eventual self-protection attempts of the Self through dissociative mechanisms.

According to Lichtenberg (2008), seeking excitement through experiences characterised by the exchange of pain, by abuse, degradation or other mental states altered by drugs is most likely associated with disorganized forms of infancy attachment or unresolved adult attachment, typically associated with serious metacognitive malfunctioning, particularly for what concerns integration capacity.

\section{Metacognitive disorders in sexual perversions}

The following description about the relationship between metacognitive malfunctioning and sexual perversions is the result of our clinical experience with patients affected by both paraphilias and sexual addiction. We did not intend it as an exhaustive or detailed discussion, rather as an example of how the metacognitive functioning can be associated with the deviations of desire or sexual behaviour. In the next chapter, instead, we will ex- 
tend this discussion to a case study, and we will include in our reflection an analysis of the IMS as well.

\subsection{Self-Reflection}

Malfunctioning of Self-reflective monitoring, for what specifically concerns the capacity of Identification, is evident in the difficulty of recognising genuine needs and real emotions (often solely described by the subject through the dichotomy "good" or "bad"), with the subsequent tendency to disguise or manage them through sexual behaviour - sexuality can thus be confused with the need for dominating or being humiliated, or with seeking love confirmations and closeness to partner. Furthermore, there can be a tendency to confuse the intensity of sexual attraction with the intensity of the emotional bond (Differentiation), or to intend sexual intensity and pleasure as the main sign of having fallen in love (Relationship among Variables). Again, physical signs linked to negative emotions can be interpreted as hints of sexual desire (Relationship among Variables) or, anyhow, with the need for acting out sexual behaviours (Differentiation). The patient may think these are obvious associations, without considering any possible alternative interpretation.

Malfunctioning of Integration makes the mind of the subjects concerned confused and dissociated, especially when they start experiencing pathological sexual desire. They gradually dissociate from reality and start playing a series of rituals which increasingly emphasize this split, favouring the loss of touch with spacetime coordinates.

Progressively, they fall into an altered state of mind (dissociation) in which they can less and less avail of their own resources and cognitive emotional faculties. As the malfunctioning increases, more and more fields are pervaded, even beyond those pertinent to sexual activity, in fact becoming increasingly pervasive in their whole life.

Furthermore, such malfunctioning occurs more and more easily, e.g. even after the simple vision of an activating stimulus. In addition to their rigid scripts for the management of their needs and emotions - which they try to manage more and more compulsively through sexual behaviour these subjects can also show rigid, repetitive and often poor manners in relating to others and in living their own lives. They lack, therefore, a wide and flexible set of narratives able to guide their own behaviour, as suggested by Lichetenberg (2008).

This is the domain of those cases for whom sexuality has the purpose to "heal" the wounds derived from disorganized mental states. As Lichtenberg 
(2008) states, children who suffered these irresolvable traumas experienced confusion, disorganised reasoning and dissociation, which interfere with the appreciation of their own and others' individuality. Instead of paying attention to the desires and feelings of others, they may tend to intensify their own negative affective states, hypervigilance and self-centredness. Alternatively, they may be subject to dissociation with emotional states such as boredom, numbness and automatic behaviours. In any case, cognition is damaged and self-reflective awareness is thoroughly lacking.

The author hypothesizes that hyperexcited states may have the function of covering up the deep emotional turmoil resulting from a deficit in sustaining empathic sensual experiences. Furthermore, both children and adults who face up to and try to manage the effect of sensual understimulation and of affective dissociation may try to re-energise themselves, among other choices, through a wide variety of sexual patterns characterised by submission-domination.

Adults with an unresolved attachment, according to Lichtenberg, struggle with their need to regulate their sensual feelings with a sexual excitement that comes in rigid and repetitive forms, which freezes them into a self-centred world characterised by immediacy.

In this dimension, the awareness of their own desires and of the behaviours aimed to seduce the other, as well as the awareness of the other's desires and individuality, are thoroughly lacking and solely existing for the purpose of an immediate regulation of their own disturbed emotional state. Stuck in such a world, characterised by a here-and-now perspective of very limited awareness, these subjects push themselves and others to enact scenarios based on sexual cravings, lacking of any possible opening to a healthy awareness of their past and future dimensions and to a reflection about possible changes.

\subsection{Mastery}

Malfunctioning of Mastery consists in the difficulty of calling on one's resources or mental abilities in order to work on one's mental states to the purpose of solving conflicts or managing problematic situations. As stated by Semerari (1999a) and Falcone, Marraffa and Carcione (2003), people tend to use the strategies they are mostly skilful at, and they sometimes will attempt to repeat them as the only way they know for problem solving. In the specific case under exam, these ways are sexual behaviours and the connected rituals.

In particular, the use of sexual behaviour to the purpose of modifying 
one's own mental states is identifiable as a first level strategy which, therefore, will require a low level reflection ability.

Such a repetitive and recurrent habit progressively limits the possibility to access superior reflection functions which, in time, will tend to fade out. In the case of sexual perversions and paraphilias the subject has very few capacities, if any at all, of voluntary self-imposition or self-inhibition, of active modification of attention, of voluntary shift of attention, as well as of identification of one's own patterns, basic beliefs and connected reflections aimed at modifying them, nor has he/she any acceptance of one's personal limitations.

\subsection{Understanding of others' mind}

For what concerns malfunctioning of Monitoring others' mind, many subjects with sexual perversions and paraphilias are mainly focussed on satisfaction of their desires, finding it difficult to put themselves in the others' place and catch their emotions and intentions (Identification). The other's mind is unclear to them and very often they may lack a real interest in understanding it. This is the reason why, for example, they underestimate or simply do not consider at all the consequences of their sexual behaviour on their partners. Such a malfunctioning can either manifest exclusively when sexual desire is activated or it may be a constant variable at the basis of a lifestyle which is neglectful, manipulative and abusive towards others. It should be observed, however, that many subjects with these disorders keep their capacity of understanding others' mind unaltered, and they feel guilty for not being able to control their behaviour in spite of this awareness. On the contrary, others exploit this capacity of understanding others' mind to their own advantage, with manipulative or seductive purposes.

Malfunctioning of Decentration can be evident in the tendency to use sex as the lens through which to interpret others' behaviours and intentions. As an example, the other can be seen as potentially in agreement while this is not happening at all in reality, or it can be imagined that the other is trying to reveal his/her own secret life. Subjects with this type of malfunctioning can increasingly project onto the other's mind their own desires and fears. Also in this case there can be subjects that maintain their decentration capacity intact and use it with the purpose of keeping their sexual behaviours hidden for a long time. 


\subsection{Metacognitive consequences}

A consequence of the above described malfunctioning can be a disorder in the capacity of figuring out goals, which is evident in making the search for sex a central activity, above all other needs. Family, professional or other types of projects become increasingly less important. As highlighted also by Carcione, Nicolò and Semerari (1999), where the subject stops working out complex life goals, sex can become a predominant and more easily reachable biological goal. Sex can thus acquire an existential value in the meaning system of these subjects, by filling a lack of meaning that, if it existed, could instead provide a sense of worth to one's life (Lambiase, 2009). Many subjects, anyway, can keep their system of values and meanings unaltered, and in this case they experience a strong conflict between the direction they would like to give to their lives on one hand and the frequent "crushes" they get on the other hand, due to their incapacity of controlling their sexual behaviours.

Another possible consequence of the described mulfunctionings can be a disorder in the capacity of sharing and belonging. Subjects may feel they cannot belong to any group even if they have some friends, towards whom, however, they do not feel a real sense of belonging. Or they can lack the meaning of relationships, which are therefore not sought to the end of establishing significant and stable bonds of affection, rather for utilitarian ends finalised to their sexual needs. As the disorder progresses, they may increasingly isolate from others, both physically and psychologically. This can make them feel more and more lonely and/or experience a growing sense of emptiness, which will lead them to seek sexual relationships in the attempt to soothe these feelings. As in the other cases analysed, also this type of disorder may not become evident, since these subjects may feel some belonging to a reference group but, due to their disorder, they also feel they are betraying or damaging them.

\section{Case study}

Marco shows clear symptoms of a Borderline Personality Disorder (BDP) at the start of the therapy sessions. He also has compulsive sexual perversions characterised by extradyadic paid sex, where he gets subdued and humiliated through non primarily sexual activities (e.g. torture of the nipples with shoe-heels or strong pinches, urination and defecation on body and face, being spit on the face, licking feet and intimate parts). During these practices he gets excited and masturbates himself in order to reach 
orgasm. At the end of these sex sessions, even though they represent an enormous source of excitement to him, he feels a sense of defeat, disgust and deep emotional emptiness. He also has non-paid extradyadic sexual experiences with women, together with whom he always and only has a dominant sexual role: he has them doing oral sex to him and exclusively penetrates them anally. Altogether, Marco's sexuality can be considered according to some authors (Shane M., Shane E. and Gales, 1999; Lichtenberg, 2008) as the possible result of a disorganised attachment and it seems strongly characterised by dissociative phenomena (Monticelli, 2005). It seems possible to hypothesize mulfunctionings in the Integration function (Dimaggio, 1999; Falcone, Marraffa and Carcione, 2003).

His sexuality with his fiancé, instead, is characterised by a childlike and passive affectivity, attention and care seeking, without the possibility of full intercourses since Marco does not consider her on a par with the other women, i.e. someone to subdue or to be humiliated by. He says:

when we go to bed in the evening Claudia always wears one of her fluffy pyjamas. I hug her tight under the blankets, we always stay like this, hugging each other tightly, with our legs interwoven, all cootchie-coo. We caress and hug each other, or we fall asleep hugged while watching TV. She is really the woman of my life, she saved me, I don't know what I'd do without her! - And again - When I come out of the shower I like that Claudia brings me my robe and wipes me off. [...] I like that she takes good care of me every day.

In spite of this, it is exactly Marco's passive and care-seeking role that also makes him perceive her partner as a watchdog ready to tell him off and give him orders on what to do and how to do it, organising his time and his social life. Therefore he reproduces the same affective dynamic of submission-domination that he experiences in his extradyadic relationships. At times he says:

I can't stand her, she's always telling me what to do...You should clean the garden, tide up the house, fix the roof, I shouldn't always be hanging about on the sofa reading books or watching telly. It's like a prison! If I could, I'd run away, I only stay because with all the debts and problems I have I wouldn't make it on my own. I can't stand this anymore!

Also in this case, Marco shows the consequences of a disorder in the Integration ability, and because of this he is not able to integrate images of the partner which are alternate and contradictory. This is what happens in the cases of disorganised attachment, as according to the dramatic triangle described by Liotti (2001). 
To summarise, Marco has a difficulty in integrating sexuality and affectivity (sexual system and attachment system) and, also within these domains, he is not able to play coherent and constant roles allowing him to experience a permanency in the desired relationships. Each role (both sexual and affective) is experienced by him as desired or exciting and as a source of discomfort and suffering at the same time. This is due on one hand to a disconnection between the two motivational systems and to an internal fragmentation of them, and on the other hand to an unsuited association with the ranking motivational system, fragmented as well and therefore inconstantly activated in connection with either attachment or sexuality. These dynamics are typical, besides, of serious disorders in the Integration skill. Furthermore, this is an example of the complex dynamics described by Monticelli and coll. (2008) in supporting the possibility of transitions of mental state, characterised by the activation of more than two motivational systems. In the example they reported, indeed, they explicitly mention a behavioural strategy which is both punitive and sexualised, and that is established in the attempt to control interactions that entail a disorganised attachment. At last, sexual pleasure is the only element Marco seeks in a constant and repetitive way, and that therefore provides a (false) sense of continuity, stability and meaning to his life, compensating for, in this way, the Integration disorders. In any case, the sexual routines Marco established in his life constitute the "glue" that allows him to experience a sense of "existence". Sex, therefore, has become for him the exclusive way through which he can manage his experience of pain, i.e. due to his inadequate emotional regulation capacities, sex has become the main, if not only, strategy he uses in order to soothe the pain of his emotional states. Besides, due to the strong emotional disregulation Marco experiences when he is in pain, he also shows a strong difficulty in recognising and assessing his own emotions (disorder in Monitoring capacity). And, again, since the sexual desire has been used repetitively and recursively for years to manage those moments, it has become the only real mind state element that Marco can clearly recognise at times of emotional hardship.

\subsection{Transcript 1}

The following transcript reports what immediately followed Marco's account of the painful episodes he experienced in the orphanage where he had lived since he was born, after being abandoned by his mother (a prostitute). The patient has very few memories of his childhood, and some of them, especially those relevant to the orphanage, are very confused and 
sometimes overlapped and recollected either in first person or seen from outside of himself - a sign that he has probably reconstructed those events. A fragmented and confuse memory, after all, is typical of post-traumatic states and of disorganised attachment.

The way the interview is conducted is typical of the InterpersonalCognitive model (Cantelmi, 2009; Cantelmi, Toro and Lambiase, 2009, 2010; Lambiase et al., 2011), according to which the relevant episodes are analysed - as suggested by Guidano $(1987,1991,2007,2008)$ - in slow motion, i.e. as through a moviola, taking into account at the same time the precious indications of Benjamin $(1996,2003)$ in the analysis of the specific behavioural units. Considering the serious disorders showed by this patient, however, the methodology has been adapted to his capabilities of analysis and assessment of the events and of his mental states.

In the following transcription we will see how the sexual motivational system gets activated in a dissociated way in Marco, inadequate to the contest particularly when specific emotional and metacognitive dynamics occur, which are dysfunctionally associated with other motivational systems. We will comment on both the patient's and the therapist's statements in order to show how the theory of motivational systems and the theory of metacognition can help the clinician in both comprehending the disorder and choosing the appropriate therapeutic actions. Marco, while trying to recollect some painful childhood episodes, suddenly stops and....

\section{P1: [silence, turns his eyes away]}

T1: [remains silent in respect of Marco's silence, perceiving however that he is "elsewhere"]

P2: [silence]

T2: Marco, how are you feeling?

P3: Uh? Well. I don't know. Well.

After Marco's silence the therapist decides to divert the attention from his past events to the present, in order to help him get back in touch with reality. In a cognitive psychotherapy we tend, indeed, to prefer keeping the patient in contact with the safety of the here and now and of the therapeutic relationship at all time while investigating the past. It is possible, from the patient's response, to hypothesize that he got detached from his story and from reality, losing the thread of narration and showing therefore a disorder in the Integration capacity, specifically for what concerns the capacity of giving a coherent tale that would describe the features of his mental state and of his evolution in the course of time, by grasping connections and causal relationships, and by characterising the cognitive and emotional elements (code A6 according to the MAS). The patient becomes absent-minded and loses the connection 
between the mental state he experiences while he reports about the past episode and his mental state at the present time.

T3: You look surprised by my question, were you thinking of anything in particular? P4: Me? Yes, I was thinking of how Adriana ${ }^{1}$ was dressed up the other day, she's really beautiful, she turned me up, if she weren't my therapist I would have try it out on her. Can I try it out on her even though she's my therapist?

There seems to be an inadequate activation of the sexual system here, further to a situation of activation of the attachment system, i.e. the recollection of traumatic past events. This is what the authors of the AIMIT manual call "disharmonic transitions" (Liotti and Monticelli, 2008). Therefore, there wasn't only a suspension of the conscience state in Marco's narration, but also an intrusion of other mental states, and this is a sign of a disorder in the capacity of integrating different mental states in a coherent narration (A7).

T4: We have already discussed this question at other times, and if you want we can talk about it again. However, in this moment I'd rather not move away from what we were talking about and I'd like to ask you how Adriana came to your mind while we were talking about your childhood. What happened?

P5: I don't know. I was thinking back to the orphanage and then ... don't know... I found myself thinking of Adriana. Uh, you know me, don't you? I'm sick! [laughing].

The therapist here decides to proceed for a multi-goal intervention. Firstly, he links the decision of not giving space to Marco's question to some previous discussion on the same subject, thus stimulating both the cooperative motivational system (those decisions had already been agreed and therefore consensual) and the capacity of integration (by creating a link with the past, when the discussion took place, and with the future, when it will be possible to talk about it again). Besides, this intervention aims at stimulating Marco's Mastery abilities, since he tends to act out as quickly as possible what he thinks or feels emotionally. At the time being, instead, also thanks to the presence of the therapist, to the stimulation of the cooperative motivational system and to Marco's - very limited but still present integration capacities, it is also possible to spur first level mastery abilities in which the therapist can use the relational context (i.e. the therapist himself who is guiding the talk) as a support (M3). The conclusive question, purposely generic, also aims at assessing Marco's awareness level at the time of his detachment from reality.

${ }^{1}$ One of the two group therapists - the group is managed by a man and a woman. 
The sequence of activation of the motivational systems and of the metacognitive disorders emerges from Marco's answer: further to the activation of the attachment system, a disorder in the Integration capacity (A6) occurs and, subsequently, the sexual system gets activated. Marco's account ends with the activation of the competitive/ranking system, since he laughs of himself (as indicated in the AIMIT manual).

T5: Let's stop for a moment now and let's analyse the scene frame by frame. You were telling me about the games you played at the orphanage, in which you were the youngest one and you were held up to ridicule and sometimes beaten up. How did you feel while you were telling me this?

P6: Nothing, I didn't feel anything.

T6: Do you remember how you felt then as a child, while you were playing those games?

P7: No, I don't remember anything.

The goal of the therapist here is to stimulate the patient's Monitoring and Integration abilities, through the investigation of the moment when and of the way how Marco lost his awareness. Marco's first answer shows a disorder in Monitoring abilities (A2) and, therefore, the therapist decides to keep working on these abilities by shifting the focus of attention to the past. He finds out the same problem here. The perception of the therapist, however, is that Marco answers too quickly and in a too shallow way. So this gives place to the doubt that it is not a real disorder in the Monitoring abilities that we find here, rather a consequence of Marco's tendency to take distance from mental states that are particularly painful, which is the consequence of a disorder in the Mastery capacity.

T7: Ok, let's try now to go even more slowly. If this can help you, close your eyes while I describe you the scene. You are a little child, your friends force you to play with them, it is a moment when the nuns are not there, and in this game they put you in the middle, they ridicule you and in a way that they make seem playful, they beat you up ${ }^{2}$.

Try to get into the scene. Now, let's take another little step back and let's go to the moment before the game with your friends starts. You are on your own and your friends call you to play with them. Describe that moment. How you feel.

P8: I'm scared, I'm trembling, I feel as sucked in from the inside. [Marco's expression is serious, as it rarely happens in the therapy sessions].

${ }^{2}$ This is a synthesis of the reformulation which, in reality, was more specific and detailed about the type of game played which, for privacy and synthesis reasons, we are not reporting here. 
To the end of stimulating Marco to get in deeper contact with the emotions he felt in that situation of discomfort, the therapist invites him to get even more into the heart of that experience, in order to verify which metacognitive disorder is preventing him from getting in touch with his emotions and, eventually, to overcome this obstacle through some expedients: slowing down the narration, focusing more deeply on details, trying to activate the cooperative motivational system - through the use of the first plural person ("let's try and go") - and the attachment system - through the use of a "caring" expression - using the therapeutic relationship in order to compensate for possible Mastery disorders. At a motivational level, if we were to translate these reflections into a phrase, it is as if the therapist said to Marco: "Let's live again your childhood together (cooperative system), I will come with you, I know it can be difficult but we are together and, if you'll need any help I'll be there for you (attachment system)"'. We believe that it is thanks to this that Marco gave himself permission to try and experience some emotions which would have been otherwise a source of unbearable pain to him.

The attachment system seems to start getting activated in Marco's tale. Besides, almost suddenly, he appears able again to identify his emotions and the physical sensations he experienced, a sign that his Monitoring capacity was only partially damaged. This would confirm the hypothesis that his capacity of recognising his own mental states was damaged in connection with some conditions of specific emotional activation, and could be favoured by the activation of the cooperative motivational system (Manaresi et al., 2008; Prunetti and Liotti, 2008).

T8: So, a feeling of fear is pervading you, you are trembling and you are feeling a sense of interior emptiness which is sucking you in. Which thoughts go through your mind?

P9: I think of the nuns, I pray that they'd come quickly because I don't want to play with the other kids, they always ill-treat me. I repeat to myself that I want them to come quickly.

The therapist, through the constant use of paraphrases, verbalisations and syntheses, tries to constantly stimulate in Marco the Self-Reflection abilities at all levels (Monitoring, Relationship among Variables and Integration). From Marco's answer it seems that his Monitoring abilities continue to be good, for he is able to identify his thoughts, emotions and physical sensations.

T9: [A veil of sadness seems to filter through Marco's serious expression and, since this is a rare occurrence, the therapist decides to notice it] How do you feel while you're telling me this?

T10: I feel like shit! 
T10: What emotion corresponds to feeling like shit? Can you describe it?

P11: I meant, what a shitty childhood I had, how sad!

T11: So you become sad while remembering yourself as a child, fearful and a victim of your friends.

P12: [Marco nods with a slightly disgusted expression].

The therapist, noting the two levels of the patient's emotional experience, fear in connection with his past and sadness in seeing himself at that time from the present, decides to temporarily shift the attention while noting also the activation - again, at the present time - of the attachment system, since Marco seems to feel sad for himself as a child. Moving to the present situation, the therapist has not only caught the chance to verify the activation of a motivational system which is often "in hiding" or dysfunctionally activated, but also the chance to stimulate the monitoring and regulation of an emotion which is hardly recognised or sustained by the patient.

T12: Let's go back to the moment when they've just called you to play. What happens then?

P13: What do you expect to have happened! I don't do or say anything. I just go and play with them otherwise it can be even worse. They would start ridiculing me and ill-treat me even harder. I just go. [In the course of the narration, clear expressions of anger start appearing on Marco's face, progressively more and more evident, until his face turns into a grin. He rhythmically and nervously moves his legs. He rubs his hands. Grinds his teeth].

Once verified the activation in the current attachment system, the therapist decides to go back to the past in order to resume the thread of narration. This choice also aims at continuing to create emotionally significant links between past and present, stimulating the metacognitive abilities of Integration. Thus, working through childhood traumas becomes one of the main therapeutic tools, which is meant to increase the narrative, metacognitive and selfreflection capacities of the patient (Onofri and Tombolini, 2006).

Getting back to the transcripts, Marco answers the therapist's question by quickly going through the system of attachment and then to the ranking system. It is possible that the attachment system remains activated in any case while Marco's anger builds up, since he keeps telling the therapist about his past sufferings. The sudden expression of anger is associated with the ranking system, and the initial perception of the therapist is that anger is addressed to him, as if he said: "What silly questions you ask me! It's obvious, how do you want me to have felt?». Anger, at least in Marco's gestures and expressions, appears to be explosive and ready to hit anyone and, most likely, the initial perception of the therapist is derived from this. 
T13: How do you feel, Marco?

P14: Bastards! Where had those nuns disappeared? I hoped they'd arrive, I was in fear, but I didn't say anything otherwise the kids would ridicule me even more and would beat me up harder. Damned!

The therapist decides to explore this anger and manages the sense of discomfort he experienced a little earlier due to his perception of being under attack by Marco.

From his reply, Marco seems to continue his simultaneous activation of the attachment system (he's scared) and of the ranking system. Marco's anger is addressed to both the nuns, i.e. whom he wished he would have been saved by, and to his friends, i.e. with whom he would have liked to play and who instead turned into his torturers. According to the model of Karpman's dramatic triangle (1968), the nuns would be the missing saviour, the friends would be the torturer and Marco the victim. In the disorganised attachment model proposed by Liotti, it is the individual - the self and the other as well - to simultaneously enclose the representations of torturer, victim and saviour. The potential saviour is missing here, therefore the torturer as well. The friends are the real torturers but always the potential saviours too or - at least in Marco's fantasy - the victims of a desired revenge, with himself as the victim who aspires to become a torturer.

\section{T14: How old were you?}

P15: I left the orphanage at the age of 6, so I must have been younger. Perhaps 5. T15: So you were a little boy, you were 5 and there were some orphanage mates who ridiculed you and beat you up for fun. You were scared and in hope that the nuns would come, but they weren't there and you didn't ask for help for fear that this would make things worse, so you kept putting up with all this.

P16: [Marco's expression is almost normal now, he seems to have become indifferent again to the emotions raised by the memory of his traumatic experience].

The therapist tries to increase the specificity of narration in order to stimulate self-reflection abilities in Marco and, at the same time, to keep the attachment system activated by both paraphrasing the narrated events and by keeping a calm and concentrated tone of voice and expression, to communicate comprehension and closeness to him.

So far, Marco's self-reflection abilities have been good. At this point, though, he seems to start taking distance from the story and from the connected emotions.

T16: How is it for you to recall this experiences? How do you feel while we are recollecting them? 
P17: Pissed off, how do you want me to feel! [from his tone of voice and expression on his face, he seems only slightly irritated, perhaps disgusted, in a way which is not proportionate to the narrated event].

T17: Imagine you could go back to that situation at your current age, what would you do to help yourself as a little boy?

P18: [his expression has now turned angry again, as it was earlier] I'd kick them all, those bastards!

Before the process of emotional detachment is complete, the therapist tries to re-focus the attention on the present in order to assess which current mental process brings the patient to dissociation. From his reply, only the ranking system seems to be activated. At metacognitive level, the dissociation is only partial, since Marco shows, indeed, signs of irritation on his face and in his tone of voice, although they are not proportionate to the narrated story and to the description of his emotion ("pissed off"), a likely sign that self-reflection abilities are present anyhow, though not thoroughly intact.

Considering the situation of this seemingly progressive emotional detachment from the past events, the therapist decides to try and assess the activation of motivational systems in connection with these painful events, to see if Marco is able to use some functional relational strategies, specifically linked to the attachment and caregiving system.

Judging from his reply, the motivational system which seems to be activated is ranking. Marco, instead of focusing on his own affective needs in that moment, dedicates his attention to the "aggressors", and decides to punish them. After feeling a victim, he now shifts within the dramatic triangle in the position of the torturer. We hypothesize that this dynamic is characterised by the simultaneous and dysfunctional activation of more than one motivational system: Caregiving (Marco acts in order to protect the child-self); Ranking (he places himself in the position of the aggressor and wishes he could punish his friends). Probably there is attachment too, since Marco is also the child-self who's feeling fearful, although he does not overtly expresses it. We hypothesize that the dysfunctional activation of the ranking system, in association with the Integration disorder (with consequent dissociation) were meant to "find a solution" to the impossibility of satisfying his intense needs of attachment and also to soothe somehow the painful emotions experienced at that time (and in similar repeated circumstances), by putting them aside and replacing them with other types of objectives and actions: surrender and/or attack in the ranking system, pleasure and excitement in the sexual system. It is also possible to hypothesise that the association with the sexual system, for what concerns the transcription under analysis, was in connection with the intrusion of seduction desires towards the therapist, emerged at the begin- 
ning of this transcript and from the analysis of other transcripts like the following one.

T18: How do you feel now, while you are telling me this?

P19: Angry, I'm furious at those kids and at the nuns. Fucking bastards!

T19: I can imagine, you must be very angry to see yourself so little while you are being so badly ill-treated, you must have felt so much fear and also anger when you were a boy. But, since you as an adult weren't there to help you, as we just imagined, how did you face up to those episodes then?

The ranking system continues to be activated.

The therapist's intervention is aimed at stimulating the self-reflective abilities in Marco and, at the same time, at responding to his attachment needs of feeling understood for his sufferings. Furthermore, the therapist is also trying to understand how Marco used to get detached from reality in the past, similarly to what he had done a little earlier when trying to assess the same fact at the present time.

P20: I don't know, I don't remember, I only remember myself playing but I haven't got the faintest idea of how it used to end up. My memory stops at the moment of the game.

T20: So, if I understood well, you were telling me earlier of the harassment you had to undergo at the orphanage and you became absent-minded and started thinking of something else in connection with the episode you are telling me now, which is making you so angry. Is this the way it went?

P21: [nods]

T21: And, if I'm not exaggerating with associations, it is possible that you used to do so as a child, since your memory stops at some point, in the same way as your awareness got interrupted while we were trying to recall it. But this is an association that just came to my mind now and we'll have the chance to investigate it further. How are you feeling now?

P22: I feel dizzy, I'm tired, let's make a break now for a while, you dazed me.

From what the patient is saying here, it seems likely that, due to his intense emotional pain, some disorders in the Integration ability have occurred, with a consequent loss of the capacity of telling a coherent story which would describe the features of his own mental state and his evolution in time.

The therapist decides to summarise the events, stimulating the Integration abilities of the patient and trying to help him understand the way he got dissociated in the present. Besides, by presenting the hypothesis as a question, therefore asking for his help to reach some conclusion, the therapist tries to stimulate the patient's cooperative system and get him out of his basically passive position of analysis and action (the victim in the Dramatic 
Triangle). The therapist also decides to share with the patient a hypothesis relevant to his past events, favouring therefore the development of integrative "bridges" between past and present thanks to the identification of some invariable elements.

The use of the motivational system theory and of the metacognitive function as a set of sub-functions allowed the therapist to reach some objectives that we deem important, not only for understanding the patient but also for the choice of therapeutic actions.

First of all, it was possible to understand at which specific moments did the disorders in the patient's self-reflection abilities manifest in the course of the activation of the attachment system (with emotions of fear and sadness). In the first case, right after the dissociation, the sexual motivational system got activated. Then, while helping him remaining in deeper touch with his painful experiences, we could notice an activation of the ranking system (with an emotion of anger). The patient is usually not able to manage the typical attachment emotions, showing metacognitive disorders (in the capacity of Integration and Monitoring) and dysfunctional activations of the ranking and sexual systems. The latter two, as we have already seen when describing the way Marco experiences sexuality and affectivity, also tend to get activated in a dysfunctional and simultaneous way. Sexuality is experienced exclusively through domination and submission, which are typical of the ranking fights. Attachment also appears tightly interwoven with ranking, with the exception of sexuality. The compensation systems, therefore, tend to get activated even simultaneously, while the attachment system gets activated according to an alternate and exclusion pattern, due to dissociative mechanisms - i.e. when the system of attachment is on, no other system appears to be activated. However it should be noted that Marco in these circumstances - as in his relationship with this fiancée manifests a basically childlike affectivity.

\subsection{Transcript 2}

The long transcription we analysed above highlighted how to work with Marco on his sexual perversions, i.e. not by just focusing on sexuality and on control of his sexual behaviours, rather by a more complex work on his metacognitive functions and on various motivational systems different from attachment. As it is evident from the previous transcript, sexuality is only brought up at specific moments and with some specific modalities.

In the following transcription, instead, we will report the analysis of a 
sexual relationship in order to show in detail the tight dysfunctional link between the motivational systems of attachment, sexuality and ranking.

T1: Tell me what happened in more detail [in his latest meeting with a private flat prostitute or escort].

P1: So, as soon as I got there I knocked on her door...

T2: Just a moment, how did you feel before knocking on her door?

P2: I was terribly excited, I had a sort of vortex in my stomach, I was agitated all over my body, my heart was beating very fast.

T3: What do you mean by "agitated"?

P3: That I was feeling like before an exam, like when the director calls me to tell me something's wrong.

T4: And what were you thinking of?

P4: I was thinking of nothing.

T5: Ok, keep going. What happened next?

P5: I knocked and then I knelt down. She opened the door and saw me. I opened my mouth and showed her my tongue. She looked at me in disgust and spat into my mouth.

T6: And how did you feel?

P6: I got even more excited all over, also physically, I had an erection.

T7: Could you describe a bit better what did you feel when this prostitute spat into your mouth? You described me the consequences, that is to say you got excited, but I haven't quite understood what did you feel, if you liked it or not to receive her saliva in your mouth.

P7: No, that was disgusting, I didn't like to receive her saliva in my mouth, I felt like a piece of shit, but that's exactly what excites me to death!

T8: What do you mean by "I felt like a piece of shit"?

P8: I mean that I felt I had been treated like a piece of shit you find on the street.

T9: And how is it to you to feel like a piece of shit on the street?

P9: You feel insignificant, it's humiliating, it's disgusting. Now that I think of it, I felt like a piece of shit about to be stamped on, so not like any piece of shit.

T10: Sure, I understand now why you were so agitated. If the pieces of shit on the street were alive I believe they'd be scared too before being stamped on. So, if I understood well, you felt humiliated for having been treated like a piece of shit and scared because you were about to be stamped on.

P10: [nods] also because I already knew what was waiting for me next.

T11: So, in that moment you were already thinking of what you would be doing next. But before we talk about it let's stop once more for a moment. We have described very well where your fear and sense of humiliation come from. Could you describe me now, as much in detail as before, what made you feel excited?

P11: It's the whole thing. I's not so much the fact I feel like a piece of shit that excites me, but to feel a piece of shit that is being stamped on, so to use the same metaphor.

T12: Let's try to stop now right on that moment when you are about to be stamped 
on, the foot is about to press you down, what is the thought that goes through your mind?

P12: "Heeeeelp" this is the thought, or "Aaaaarrrghh". I mean, something like this.

T13: So, the foot is about to stamp you down, you are scared, your body trembles and you feel excited. What do you do then?

P13: I start masturbating myself.

T14: Could you explain this a bit better?

P14: This is what I do in reality, not on the door while she's spitting in my mouth, I'm not so stupid, I do that inside, when we do all the rest.

T15: Which is?

P15: When she squeezes my nipples or stamps on them with her heels [sometimes to the point of making them bleed, but with no serious wounds], when she urinates or defecates on my face, you know.

It appears, from the patient's tale, that the activated motivational systems are attachment - since he is scared - sexual - since he is excited, masturbates himself and reaches orgasm - and ranking - since he gets humiliated and subdued. In particular, it looks as if the very activation of the ranking system, with consequent frustration and subversion of the attachment needs (he is afraid but instead of looking for reassurance he makes himself being "attacked"), is at the basis of Marco's excitement states. As we already reported, we would like to highlight that in our view the link between these three motivational systems is so tight that we believe it would be impossible to work therapeutically at sexual level only. It is, rather, necessary to dedicate specific attention to the other motivational systems. The ranking dynamics will have to be recognised and faced outside of the sexual domain, as well as the attachment needs. Furthermore, specific attention will need to be dedicated to the needs and strategies of the cooperative system, since it doesn't seem to be ever active at all. This work can be done either by discussing about his life in the therapy sessions, as we have seen in the first transcript, or through clinical dialogue.

\section{Conclusions}

In the present work we intended to show the advantages of an analysis of sexual perversions conducted in terms of motivational systems and of metacognitive functioning. In our view, this methodology allows a higher specificity and clarity in identifying the patient's problems and their origin, as well as the possible therapeutic interventions. It was possible to identify dynamics and disorders that usually occur out of the sexual domain in the patient's life and that, therefore, need a specific and dedicated therapeutic 
attention. We find too often, instead, a tendency to treat sexual problems as exclusively and reductively sexual, with a consequent reduction of the possibilities for change.

In conclusion, it was possible to also recognise dynamics that are not at all or too little manifest in Marco's life and that, instead, could be of great help to him, in particular those referring to the cooperative motivational system, such as social game and group affiliation dynamics, as well as interpersonal and attribution of meanings dynamics (Liotti and Monticelli, 2008). Marco's life is indeed almost exclusively focused on sex. He has no interests, no friends or groups he feels he belongs to, nothing else than sex is meaningful to him and he defines himself without taking others into account with the exception, sometimes, of his fiancée.

Furthermore, the association with metacognitive functioning allowed us to identify those dysfunctions that not only influenced the disorder, but which would have put the therapy in jeopardy: it is difficult, if not impossible, for a patient with an emotional regulation disorder to be able to follow some therapeutic indications; and it is also very complex for a patient with an integration capacity disorder to be able to maintain, through the therapy sessions, a thread of meaning in the various tasks given. On the other hand, the same problem could be due to an emotional regulation disorder - with consequent access of intense and disturbing emotions to the patient's conscience, which deviate his intentional flow of thoughts - or to a disorder in the capacity of reading his own mind - with a consequent difficulty in maintaining an internal permanence of his own needs, emotions and motivations worked out in the therapy. To be able to understand the malfunctioning behind the symptom not only allows to better comprehend the disorder, but also to select the best therapeutic intervention, both during the sessions and as a homework.

The main limitation of a single-case study is, obviously, generalisation. It is in order to compensate for this limitation that we dedicated much space to theoretical explanations. It would be interesting and useful, in order to deepen our hypothesis and argumentations, to carry out an investigation on a wider scale using an integration of the assessment scales of metacognitive functioning (MAS) and of motivational systems (AIMIT) which were developed by the same authors of the models we used.

\section{Abstract}

In this study we will show how to conceptualize a Borderline Personality Disorder case with sexual perversions in terms of Interpersonal Motivational Systems and 
of Metacognitive functioning models, in order to allow a more targeted and effective clinical treatment. To this end, after a theoretical discussion we will analyse some psychotherapy transcripts.

In order to support our reflections and therapeutic choices we decided to refer to the metacognitive functioning model according to the MetacognitiveInterpersonal model (Semerari, 1999b; Dimaggio and Semerari, 2003; Carcione et al., 2008; Dimaggio et al., 2008; Dimaggio et al., 2009) and to the Interpersonal Motivational Systems theory within the Cognitive-Evolutionary model (Lichtenberg, 1989; Lichtenberg, Lachman and Fosshage, 1992, 1996; Liotti, 2001, 2005; Liotti, Cortina and Dazzi, 2008).

Key words: metacognition, sexual perversions, interpersonal motivational systems, sexual addiction, attachment.

\section{References}

Ammaniti M., Nicolais G. and Speranza A. (2007), Attachment and sexuality during adolescence, in Diamond D., Blatt S.J. and Lichtenberg J. (eds.), Attachment and sexuality, New York: The Analytic Press, 79-105.

Benjamin L.S. (1996), Interpersonal diagnosis and teratment of personality disorders. II edition, New York: Guilford Press (trad. it. Diagnosi interpersonale $e$ trattamento dei disturbi di personalità, LAS, Roma, 1999).

Benjamin L.S. (2003), Interpersonal reconstructive therapy. Promoting change in nonresponders, New York: Guilford Press (trad. it. Terapia ricostruttiva interpersonale. Promuovere il cambiamento in coloro che non reagiscono, LAS, Roma, 2004).

Cantelmi T. and Lambiase E. (2007), "Legame affettivo e comportamento sessuale. Come lo stile di attaccamento influenza il comportamento sessuale", Psicoterapia e Scienze Umane, 41, 2: 205-228.

Cantelmi T. (2009), Manuale di Psicoterapia Cognitivo-Interpersonale. Prospettive di integrazione, Alpes Italia, Roma.

Cantelmi T., Toro M.B. and Lambiase E. (2009), "Priscilla: un caso di bulimia inquadrato secondo il modello cognitivo interpersonale", Idee in Psicoterapia, 2, 2 : 137-148.

Cantelmi T., Toro M.B. and Lambiase E. (2010), "Il 'vaso di Pandora': utilizzo dell'Auto Osservazione Strategica in una paziente con Disturbo Alimentare", Modelli per la Mente, in corso di pubblicazione.

Carcione A., Dimaggio G., Fiore D., Nicolò G., Procacci M., Semerari A. and Pedone R. (2008), "An intensive case analysis of client metacognition in a good-outcome psychotherapy: Lisa's case", Psychotherapy Research, 18, 6: 667-676. DOI: 10.1080/10503300802220132

Carcione A., Dimaggio G., Conti L., Nicolò G., Semerari A. (2010), Scala di Valutazione della Metacognizione (SVaM). Manuale per la siglatura V 4.0, Manoscritto non pubblicato.

Carcione A., Nicolò G. and Semerari A. (1999), Deficit di rappresentazione degli 
scopi, in Semerari A. (a cura di), Psicoterapia cognitiva del paziente grave. Metacognizione e relazione terapeutica, Milano: Raffaello Cortina, 41-164.

Cassidy J. and Shaver P.R. (eds.) (1999), Handbook of attachment: Theory, research, and clinical applications, New York: Guilford (trad. it., Manuale dell'attaccamento. Teoria, ricerca e applicazioni cliniche, Fioriti, Roma, 2002).

Crittenden P. (2002), "Transformaciones en las relaciones de apego en la adolescencia: Adaptación frente a necrsidad de psicoterapia”, Revista de Psicoterapia, 12: 33-62.

Crittenden P. and Landini A. (2011), Assessing Adult Attachment. A dynamic maturational approach to discourse analysis, New York: Norton and Company.

Del Giudice M. (2009), "Sex, attachment, and the development of reproductive strategies", Behavioral and Brain Sciences, 32: 1-67. DOI: 10.1017/S0140525X09000016

Diamond D., Blatt S.J. and Lichtenberg J.D. (eds.) (2007), Attachment and sexuality, New York: Lawrence Erlbaum Associates.

Dimaggio G. and Semerari A. (a cura di) (2003), I disturbi di personalità. Modelli e trattamento, Laterza, Roma.

Dimaggio G., Lysaker P.H., Carcione A., Nicolò G. and Semerari A. (2008), "Know yourself and you shall know the other... to a certain extent: Multiple paths of influence of self-reflection on mindreading", Consciousness and Cognition, 17: 778789. DOI: $10.1016 /$ j.concog.2008.02.005

Dimaggio G., Vanheule S., Lysaker P.H., Carcione A. and Nicolò G. (2009), "Impaired self-reflection in psychiatric disorders among adults: a proposal for the existence of a network of semi independent functions", Consciousness and cognition, 18, 3: 653-664. DOI: 10.1016/j.concog.2009.06.003

Dimaggio G. (1999), Il problema dell'integrazione: Il deficit della funzione narrativa, in Semerari A. (a cura di), Psicoterapia cognitiva del paziente grave. Metacognizione e relazione terapeutica, 187-230, Milano: Raffaello Cortina.

Eagle M. (2005), “Attaccamento e sessualità", Psicoterapia e scienze umane, 39, 2: 151-164.

Falcone M., Marraffa M. and Carcione A. (2003), Metarappresentazione e psicopatologia, in Dimaggio G. and Semerari A. (a cura di), I disturbi di personalità. Modelli e trattamento, Roma: Laterza, 43-76.

Fonagy P. and Target M. (2001), Attaccamento e funzione riflessiva, Milano: Raffaello Cortina.

Guidano V.F. (1987), Complexity of the self, New York: Guilford (trad. it. La complessità del sé, Torino: Bollati Boringhieri, 1988).

Guidano V.F. (1991), The self in process, New York: Guilford (trad. it. Il sé nel suo divenire, Torino: Bollati Boringhieri, 1992).

Guidano V.F. (2007), Psicoterapia cognitiva post-razionalista. Una ricognizione dalla teoria alla clinica, Milano: Franco Angeli.

Guidano V.F. (2008), La psicoterapia tra arte e scienza. Vittorio Guidano insegna "come si fa” la psicoterapia cognitiva post-razionalista, Milano: Franco Angeli.

Karpman S.B. (1968), "Fairy tales and script drama analisys", Transactional Analysis Bullettin, 7: 39-43.

Lambiase E. (2009), La dipendenza sessuale. Nuovi modelli clinici e proposte di intervento terapeutico, Roma: LAS ( $1^{\mathrm{a}}$ ed. 2001).

Lambiase E., Toro M.B., Pensavalli M. and Cantelmi T. (2011), "La tecnica dell'AutoOsservazione Strategica secondo il modello Cognitivo-Interpersonale", Modelli per la Mente, 4(1): 13-30. 
Lichtenberg J.D. (1989), Psychoanalysis and Motivation, Hillsdale, NJ: Analytic Press.

Lichtenberg J.D. (2008), Sensuality and sexuality across the divide of shame, New York: The Analytic Press.

Lichtenberg J.D., Lachmann F. and Fosshage J. (1992), Self and Motivational Systems. Toward a Theory of Psychoanalytic Technique, Hillsdale, NJ: The Analytic Press.

Lichtenberg J.D., Lachmann F. and Fosshage J. (1996), The Clinical Exchange, Hillsdale, NJ: Analytic Press.

Lieberman A.F. (1996), "Aggression and sexuality in relation to toddler attachment: Implications for the caregiving system", Infant Mental Health Journal, 17: 276292. DOI: 10.1002/(SICI)1097-0355(199623)17:3<276::AID-IMHJ6>3.0.CO;2-M

Liotti G and Monticelli F. (a cura di) (2008), I sistemi motivazionali nel dialogo clinico. Il manuale AIMIT, Milano: Raffaello Cortina.

Liotti G., Cortina M. and Dazzi N. (2008), Intersoggettività e sistemi motivazionali. Una prospettiva evoluzionista e neojacksoniana, in Liotti G. and Monticelli F. (a cura di), I sistemi motivazionali nel dialogo clinico. Il manuale AIMIT, Milano: Raffaello Cortina, 20-42.

Liotti G. (2001), Le opere della coscienza. Psicopatologia e psicoterapia nella prospettiva cognitivo-evoluzionista, Milano: Raffaello Cortina.

Liotti G. (2005), La dimensione interpersonale della coscienza, Roma: La Nuova Italia Scientifica (1 ${ }^{\mathrm{a}}$ ed. 1994, Roma: Carocci).

Mahler M.S., Pine F. and Bergman A. (1975), The psychological birth of the human infant: Symbiosis and individuation, New York: Basic Books.

Main M. (1991), Metacognitive knowledge, metacognitive monitoring, and singular (coherent) vs. multiple (incoherent) model of attachment: findings and directions for future research, in Parkes C.M., Stevenson-Hinde J., Marris P., Attachment across the life cycle, New York: Routledge, 127-159.

Manaresi F., Cotugno A., Onofri A. and Tombolini L. (2008), Le forme della mentalizzazione nei contesti interpersonali. Uno studio sui rapporti fra sistemi motivazionali e funzioni metacognitive, in Liotti G. and Monticelli F. (a cura di), I sistemi motivazionali nel dialogo clinico. Il manuale AIMIT, Milano: Raffaello Cortina, 65-82.

Monticelli F. (2005), Le perversioni sessuali nella prospettiva cognitivo evoluzionista, Psicobiettivo, 25, 1: 117-131.

Onofri A. and Tombolini L. (2006), Pensare la mente. EMDR e Psicoterapia cognitivoevoluzionista, in Balbo M. (a cura di), EMDR. Uno strumento di dialogo terapeutico, Milano: Mc-Graw Hill.

Prunetti E. and Liotti G. (2008), Effetti sulla metacognizione della costruzione di un dialogo collaborativo: analisi di una seduta di psicoterapia, in Liotti G. e Monticelli F. (a cura di), I sistemi motivazionali nel dialogo clinico. Il manuale AIMIT, Milano: Raffaello Cortina, 83-98.

Roiphe H. and Galenson E. (1981), Infantile origins of sexual identity. New York: International Universities Press.

Semerari A. (1999a), Deficit di regolazione emotiva, in Semerari A. (a cura di), Psicoterapia cognitiva del paziente grave. Metacognizione e relazione terapeutica, Milano: Raffaello Cortina, 313-342.

Semerari A. (a cura di) (1999b), Psicoterapia cognitiva del paziente grave. Metacognizione e relazione terapeutica, Milano: Raffaello Cortina. 
Semerari A., Carcione A., Dimaggio G., Nicolò G. and Procacci M. (2007), “Understanding minds: Different functions and different disorders? The contribution of psychotherapy research", Psychotherapy Research, 17, 1: 106-119. DOI: 10.1080/ 10503300500536953

Shane M., Shane E. and Gales M. (2001), "Sesso, sessualizzazione e il feargasm. Un approccio alla sessualità secondo la psicologia del sé e la teoria dei sistemi dinamici evolutivi”, Rivista Italiana Telematica di Psicologia Psicoanalitica del Sé, Intersoggettività, Psicoanalisi Relazionale, 3: 1.

Shaver P.R. and Hazan C. (1992), Adult romantic attachment process: theory and evidence, in Perlmen D. and Jones W. (eds.), Advances in personal Relationship Outcomes, 4: 29-70. London: Jessica Kingsley Publisher (trad. it.: L'attaccamento di coppia negli adulti. Teoria ed evidenza empirica, in Carli L. (a cura di) (1995), Attaccamento e rapporto di coppia. Milano: Raffello Cortina, 43-88).

Shaver P.R., Hazan C. and Bradshaw W. (1988), Love as attachment. The integration of three behavioral systems, in Sternberg R. and Banres M. (eds.), The psychology of love, New Haven, CT: Yale University Press.

Steinberg L. (2005), "Cognitive and affective development in adolescence", Trends in Cognitive Sciences, 9, 2: 69-74. DOI: 10.1016/j.tics.2004.12.005

Tombolini L. and Liotti G. (2000), "L’influenza delle esperienze di attaccamento infantili sulla sessualità adulta", Rivista di Sessuologia, 24, 4: 317-330.

Weiss R. (1982), Attachment in adult life, in Parkes C., Stevenson-Hinde J. and Marris P. (eds.), Attachment across the life cycle, London: Routledge (trad. it., L'attaccamento nel ciclo della vita, Roma: Il Pensiero Scientifico, 1995). 